\title{
AC 2008-2567: A MULTIDISCIPLINARY LABORATORY COURSE: ROBOTIC DESIGN AND PROGRAMMING WITH MINDSTORMS
}

\section{Nebojsa Jaksic, Colorado State University-Pueblo}

Nebojsa I. Jaksic received the Dipl. Ing. degree in electrical engineering from Belgrade

University in 1984, the M.S. in electrical engineering, M.S. in industrial engineering, and Ph.D. in industrial engineering from the Ohio State University in 1988, 1992, and 2000, respectively.

From 1992 to 2000 he was with DeVry University in Columbus, OH. In 2000, he joined Colorado State University-Pueblo, where he is currently an Associate Professor and the mechatronics program director. Dr. Jaksic's interests include mechatronics and nanotechnology education and research. He is a member of ASEE, IEEE, SME, and MRS.

\section{Dawn Spencer, Colorado State University-Pueblo}

Dawn E. Spencer received B.S. and M.S. degrees in computer science from The Ohio State University in 1990 and 1992 respectively. After working as an independent contractor for many years for companies ranging in size from family businesses to IBM, Dawn accepted a position at Colorado State University - Pueblo in 2000, where she is currently an Assistant Professor in the CIS department of the Hasan School of Business. She is a member of ISSA and ASEE. 


\title{
A Multidisciplinary Laboratory Course: Robotic Design and Programming with Mindstorms
}

\begin{abstract}
This work describes an introductory mechatronics/computer information systems laboratory course, Robotics with LEGO Mindstorms NXT, offered in Fall 2007. The course is designed to employ discovery-based learning in a multidisciplinary environment using robots. A current, high-profile, engineering problem, DARPA Urban Challenge, was selected to motivate students. The challenge was modified to fit the LEGO Mindstorms robotic environment available for the course. A configurable route consisting of modular route segments was developed. Our assessment metrics show exceeding of the learning objectives set for the course and high student satisfaction.
\end{abstract}

\section{Introduction}

To facilitate discovery-based learning, learning in a multidisciplinary environment, and promote further development of graphical programming skills, a Robotics with LEGO Mindstorms NXT course was developed and implemented. This is a two-hour laboratory, one semester, upper division course offered within two programs at the Colorado State University - Pueblo: the Bachelor of Science in Engineering with specialization in Mechatronics program and the Computer Information Systems program.

This course was inspired by an actual robotics competition, the Defense Advanced Research Project Agency's (DARPA) Urban Challenge, a 2007, \$2,000,000 prize autonomous vehicle challenge to complete 60 miles in traffic in less than six hours. The challenge took place on November $3^{\text {rd }}$ at Southern California Logistics Airport.

\section{Previous Work and Justification}

The major function of the Robotics with LEGO Mindstorms NXT course is to promote discovery-based active learning and knowledge systematization. Robot building is a powerful student motivational tool ${ }^{1}$. Mimicking an actual multimillion-dollar robotic prize competition ${ }^{2}$ further enhances student motivation. A set of new tools like LEGO Mindstorms Education Base Set with NXT technology (became available in August 2006) and the National Instruments LabVIEW Toolkit for LEGO Mindstorms NXT (became available for downloads in midDecember 2006) are implemented in this novel engineering design course.

The Robotics with LEGO Mindstorms NXT course is a part of the pedagogical system implemented in our Mechatronics curriculum. This pedagogical system is based on McCarthy's ${ }^{3}$ version of the $\mathrm{Kolb}^{4}$ learning cycle and was motivated in part by work presented by Harb et al $\mathrm{l}^{5}$. New concepts can be learned by following a pattern called the learning cycle exemplified by the questions why, what, how, and what if. Active discovery-based learning is considered an important part of this learning cycle, especially in engineering ${ }^{6}$. Bruner ${ }^{7}$ defines discovery 
learning as a cognitive instructional model whereby students are empowered and encouraged to learn concepts and principles through active hypothesis testing and discovery.

Engineering laboratory courses use active learning. Often, open-ended projects are used as powerful pedagogical tools for discovery-based learning. To minimize the time to build prototypes and to minimize the cost of such projects by using low-cost plastic parts and enforcing reusability of parts, many instructors adopted LEGO bricks and LEGO computerized systems as educational tools. A large body of engineering education research describes the use of LEGO brick $^{8}$. Most examples use LEGO Mindstorms RCX with the Robolab programming environment (RIS 2.0) based on National Instruments LabVIEW software for various projects and courses like robot competitions ${ }^{9,10}$, programming ${ }^{11,12}$, and project-based learning ${ }^{13-19}$. The literature reviewed shows positive results like increased student enthusiasm towards engineering, perceptual and actual increase in students' knowledge, and development of design and team skills. However, LEGO Mindstorms RCX is restrictive for more advanced projects in both hardware and software. A number of third-party solutions were proposed to increase its flexibility $^{12,20}$.

LEGO's response to a need for an improved microcontroller system is addressed in their new LEGO Mindstorms NXT product. The older LEGO Mindstorms RCX is obsolete. LEGO stopped its production and any further developments in favor of LEGO Mindstorms NXT. While the ideas from literature using old LEGO Mindstorms RCX sets are still valid, the implementations are quickly becoming dated. Hardware and software capabilities of the new LEGO Mindstorms NXT with some new, interesting, and useful features are described elsewhere ${ }^{21,22}$.

\section{Curriculum Context of Robotics with LEGO Mindstorms NXT Course}

Robotics with LEGO Mindstorms NXT is a two-hour laboratory one-semester junior/seniorstanding course available within the recently offered Bachelor of Science in Engineering with specialization in Mechatronics (BSE-Mechatronics) program at the Colorado State University Pueblo was cross-listed under the Bachelor of Science in Computer Information Systems (CIS).

To facilitate discovery-based learning and promote further development of graphical programming skills introduced in a previous course on mechatronics, a course, Robotics with LEGO Mindstorms NXT, is designed and implemented. Some of the specific discovery-based learning objectives for this course are to increase the practical knowledge of basic robot controls and robotic interfacing with their surrounding.

In their first year's Introduction to Engineering course, students were exposed to an older LEGO Mindstorms RCX environment allowing them to transfer some of the experience to the new system. CIS students are currently in, or finished with, an advanced programming course and are already familiar with programming structures. Course grading is based on fulfilling criteria from the actual DARPA Urban Challenge announcement ${ }^{2}$, progress reports, and a final presentation with report. 


\section{Laboratory Assignment}

This laboratory course is designed to develop student engineering design and graphical programming skills, and to specifically provide practical experience with basic robotic controls and robot interaction with its surroundings. The inspiration for the experiment comes from DARPA's Urban Challenge. The experiment requires one LEGO Mindstorms NXT set per team with additional sensors available if desired.

$\underline{\text { Laboratory Task: }}$

A robot is to be constructed and equipped with a sufficient number of sensors to be able to navigate the streets of a miniature city. The robot should include at least two types of sensors: a number of light sensors for detecting curbs, stop lines, no-passing and passing lines, and turning lanes, as well as at least one ultrasonic sensor for sensing other traffic on the road like parked cars, cars waiting to turn, cars coming from the opposite direction, etc. A portion of a city model with modular sections consisting of various street types and intersections including START and FINISH positions will be provided. A description of the desired route will also be provided. The robot is to operate as follows:

1. An executable NXT program based on the route description should be created and stored into the robot memory.

2. After placing the robot at the START position the robot should be turned on.

3. Then, the robot should follow the prescribed route based on the route description. The choice of type and number of sensors is open.

4. When the robot reaches the FINISH position, it will execute a parking maneuver resulting in the robot being parked in a parking spot.

Hardware and software designs are not further specified.

The rules for the Mindstorms NXT DARPA Urban Challenge are constructed from a subset of the DARPA Urban Challenge rules, specifically from the Required Behaviors Section: Basic Navigation and Basic Traffic ${ }^{2}$. If it is assumed that an average car is about $4 \mathrm{~m}$ long and the designed Mindstorms NXT robot is about $0.2 \mathrm{~m}$ long, than the ratio of lengths between the two is about 20:1. Therefore, the original DARPA Urban Challenge rules are scaled down at least 20 times for distances.

1. Required modified basic navigation rules are as follows.

a) Robot stays entirely within its travel lane around corners.

b) Robot stops within $0.05 \mathrm{~m}$ of stop lines.

c) At an intersection, robot exhibits less than 10 seconds of delay when intersection is clear.

d) Robot completes passing maneuver around a stationary obstacle (of similar size to robot) within the modular section maintaining a safety buffer of $0.1 \mathrm{~m}$ in front of and behind obstacle.

e) Robot perpendicular parks in a designated parking spot.

2. Required modified basic traffic rules are as follows.

a) Robot stops between $0.1 \mathrm{~m}$ and $0.25 \mathrm{~m}$ behind a stopped lead vehicle.

b) Robot travels at least half its maximum speed on straight-aways.

3. Optional modified basic navigation rules are as follows.

a) Robot stops within $0.05 \mathrm{~m}$ of stop signs. 
b) Robot completes passing maneuver around a moving obstacle within the modular section(s) maintaining a safety buffer of $0.1 \mathrm{~m}$ in front of and behind obstacle.

c) Robot parallel parks in a designated parking spot.

4. Optional modified basic traffic rules are as follows.

a) Robot exhibits correct precedence order at an intersection, i.e. the first vehicle to reach a stop line is the first to leave.

b) Robot maintains a safety buffer of $0.3 \mathrm{~m}$ when traveling.

LEGO Mindstorms NXT Specifications are summarized in literature ${ }^{21,22}$.

\section{$\underline{\text { Route configuration: }}$}

To provide a variety of navigational situations, a set of miniature route segments was constructed for this course to allow construction of configurable routes in a matter of seconds. These segments are assembled in different configurations, thus creating different routes and tasks for robots. Figure 1 depicts some of the route segments used to assemble a route for testing the navigational capabilities of robots. Clockwise from top-left, the segments shown are a three-way intersection, a street with a passing lane, a straight street, and a four-way intersection ${ }^{22}$. New modules include a straight street segment with parallel parking, a perpendicular parking lot, and a 90-degree curve. Obstacles simulating other vehicles may be placed at any point to obstruct traffic. An actual configuration used to test the robots is shown in Figure 2.

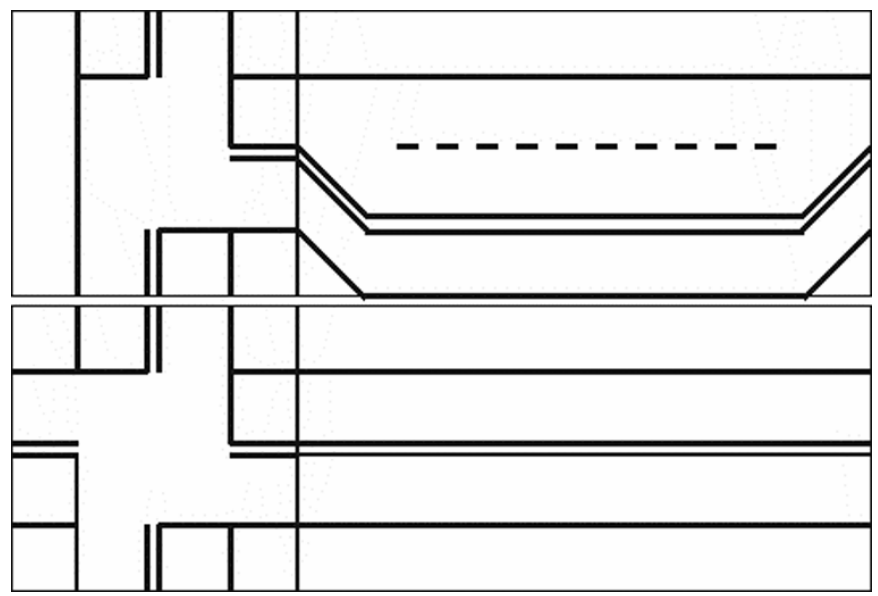

Figure 1. Four route segments for testing navigational capabilities of robots 


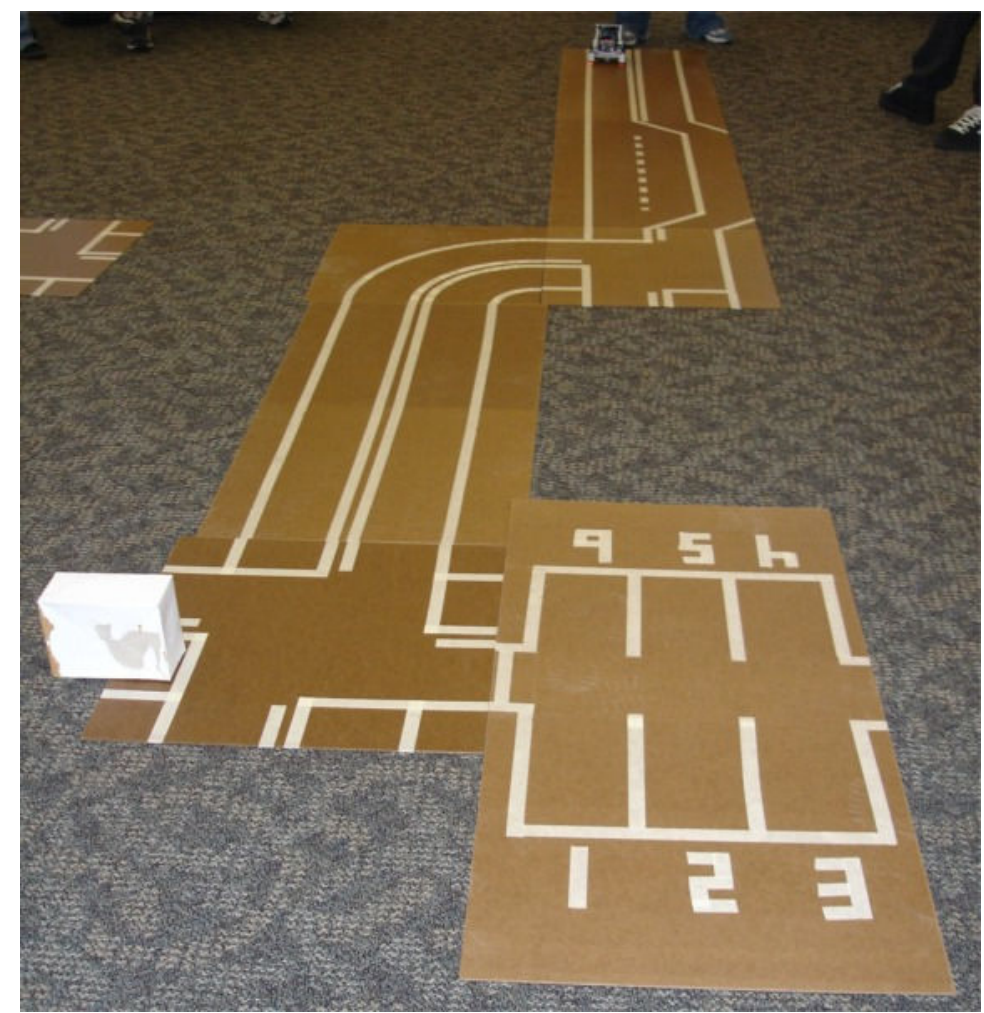

Figure 2. One route configuration

\section{Results}

Engineering and computer information systems students of sophomore, junior, senior, and graduate standings took the course. Students constructed and programmed robotic vehicles to traverse a miniaturized route using LEGO Mindstorms NXT sets. Some final robot designs are shown in Figure 3.

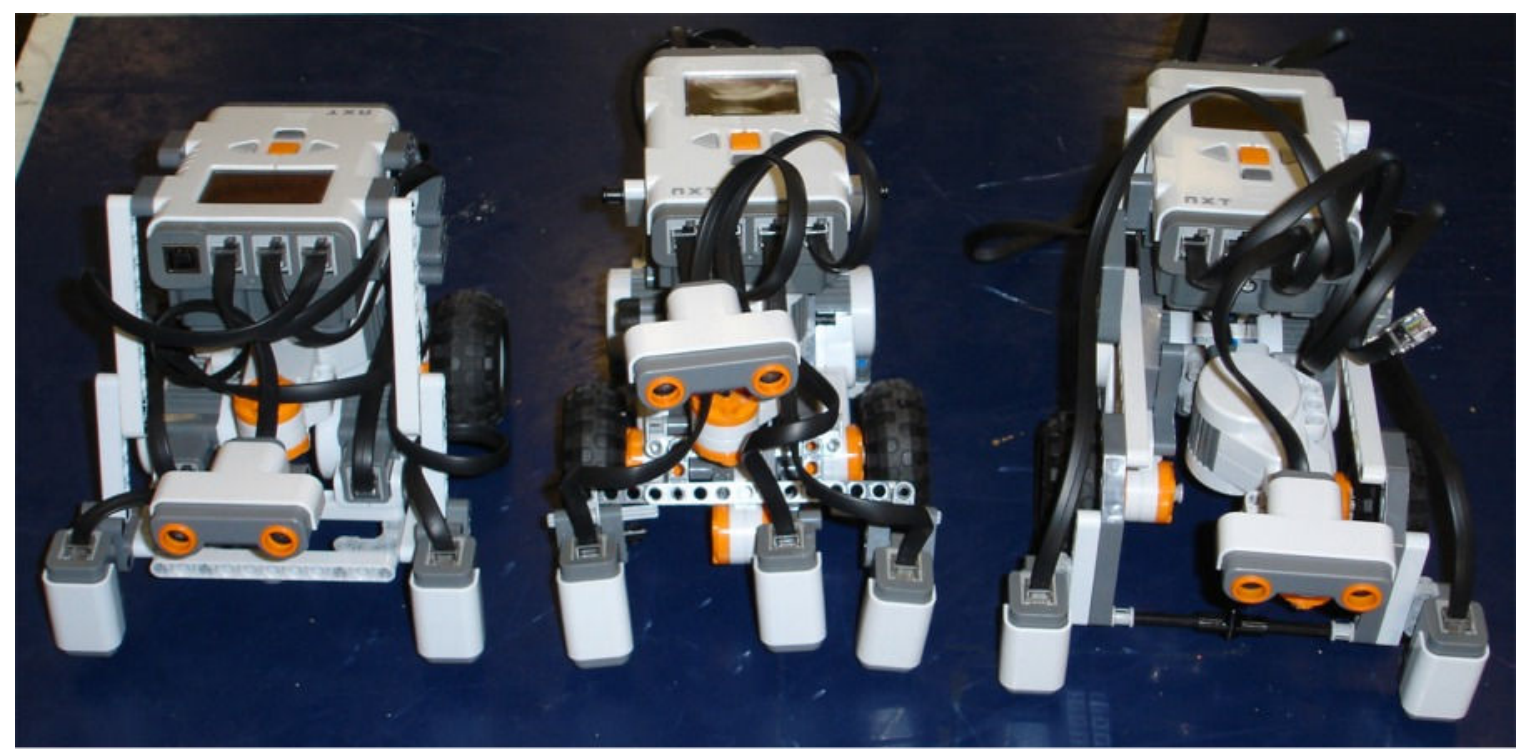

Figure 3. Some final robot hardware designs 
Appropriate assessment instruments are developed. Their goals are to re-evaluate widely-known results from literature as the instruments are applied in this particular case (motivation, learning perceptions, quality of learning experience) as well as the specific laboratory objectives such as the degree of increase in practical knowledge of basic robot controls, multisensor data fusion, and robot programming.

Both formative and summative assessment evaluation techniques are addressed. Formative evaluations are based on informal student interviews, topic discussions, questions raised, and biweekly progress reports discussing milestones met. Summative evaluations are based on final robot performance measures (degrees to which the robots satisfy criteria stated in the Laboratory Task Section), a final team presentation with report, a survey (student perceptions of lab effectiveness, suitability, and motivational value), and university-standard student evaluations of teaching for the entire course.

A survey was administered to students at the conclusion of the course. It was adapted from a Drexel University form ${ }^{23}$. The survey with average student responses is shown below. The scale used for the survey was 1 to 5. Where 1 indicates 'Not at All', 2 indicates 'To a Limited Extent', 3 indicates 'To a Moderate Extent', 4 indicates 'To a Great Extent', and 5 indicates 'To a Very Great Extent'.

Item

1 Analytical Skills Applies logic in solving problems and analyzes problems from different points of views. Translates academic theory into practical applications using appropriate technical techniques, processes, and tools.

2 Communication Skills Articulates ideas in a clear and concise fashion and uses facts to reinforce points. Written materials flow logically and are grammatically correct. Plans and delivers oral presentations effectively. Uses technology and graphics to support ideas and decisions.

3 Creative Problem-solving Develops many potential solutions to problems while discouraging others from rushing to premature conclusions. Suggests new approaches and challenges the way things are normally done.

4 Life-Long Learning Learns independently and continuously seeks to acquire new knowledge. Exceeds basic requirements of an assignment and brings in relevant outside experiences to provide advanced solutions to the problems at hand

5 Project Management

Sets goals, prioritizes tasks and meets project milestones. Seeks clarification of task requirements and takes corrective action based upon feedback from others. Creates action plans and timetables to complete assigned work.
Avg. 
6 Research Skills

Uses computer based resources effectively thus acquiring information from multiple sources and organizes and interprets data appropriately. Designs and conducts experiments to validate theories.

7 Systems Thinking

Understands how events interrelate and demonstrates an ability to take new information and integrate it with past knowledge. Integrates and uses knowledge from various courses, including Engineering, CIS, Physics, Mathematics, and Social Sciences, to solve technical problems.

8 Teamwork

Each member contributes a fair share to the completion of the project. Everyone participates, listens and cooperates with other members. Members share information and help reconcile differences of opinions when they occur.

9 Do you have a better understanding of engineering from this course?

10 Do you have a better understanding of computer information systems from this course?

11 Did you understand the objectives of your project?

12 Did your team meet the objectives of the project?

13 Did your team meet the milestones?

14 Do you feel your technical writing skills have benefited from the course?

15 Do you feel your oral communication abilities have improved by taking the course?

16 Have your computer skills improved by taking the course?

3.75

17 Do you understand the process of solving an engineering/programming problem?

18 Did you ask for help when or if you did not understand something?

19 Do you feel you contributed greatly to the project?

20 Did you enjoy working on a team?

21 Did your participation on the team help or hinder your performance and the end result of the project?

22 Do you understand the importance of having a planning/design phase before an implementation phase?

23 Do you feel that expectations were too high?

24 Do you feel like there was too much work?

25 Was the course relevant to your interests?

26 Did the course stimulate your interest in engineering/CIS/robotics?

27 Understand various aspects of hardware/software integration

28 Able to develop criteria for the selection, justification, and implementation of selected technology methods and processes to perform a design task

29 Capable of using commercially available hardware/software tools for robotics

30 Able to build and program robots for independent research in robotics

Results were positive with an overall average of 4.17 on a scale of 1 to 5 . The points with the highest average scores, 4.75 or higher, were: 
- Was the course relevant to your interests?

- Did the course stimulate your interest in engineering/CIS/robotics?

- Do you feel you contributed greatly to the project?

- Systems Thinking

- Creative Problem-solving

- Analytical Skills

This indicates a high level of interest and effort in the class throughout the semester.

Besides igniting interest in robotics for the students in the class, we had an unintended effect of exciting a class of about 24 preschool children who came to participate in a final testing stage.

During the official DARPA Urban Challenge on Saturday, November $3^{\text {rd }}, 2007$, the students held their own mini Urban Challenge in the lobby of the student dorm. Although it was interesting for onlookers, results were not as hoped due to the early date. In one case, the robot traversed the entire route, but didn't detect another vehicle at an intersection. The obstacle didn't reflect the ultrasound back to the robot's sensor. In another case, results were inconsistent; the robot performed differently each time through the route, possibly due to varying lighting conditions.

Robotics projects are an effective educational tool for discovery-based learning. While all students were enthusiastic about the course, they felt that the material was overwhelming for a one-credit course, and that they needed more structure. A considerable amount of unscheduled laboratory time is needed to complete the project. It was found that while easy to use for simple tasks, the LEGO Mindstorms NXT software is somewhat cumbersome for more complicated programs. In the future, based on these comments and our own observations, the course will be implemented as a two credit hour course containing one lecture hour in addition to the two lab hours per week.

\section{Conclusions}

In this paper, a robotics laboratory design course implementing a new hardware/software environment, the LEGO Mindstorms NXT, is presented. The course laboratory task combines robotic navigation tasks coupled with obstacle detection and avoidance tasks. Discovery-based learning objectives dealing with robot controls and simple multisensor data fusion are satisfied. Student comments are positive, and the project setup is cost-effective (about $\$ 300$ per setup). Based on student responses, this research confirms that robotics projects are an effective educational tool for discovery-based learning. However, the one credit hour offering for this robotic course is not adequate; thus, it will be increased next time the course is offered.

\section{Bibliography}

1. Pomalaza-Raez, C., and Groff, B. H., "Retention 101: Where Robots Go ... Students Follow," Journal of Engineering Education, vol. 92, No. 1, January 2003, pp.85-90.

2. http://www.darpa.mil/grandchallenge/index.asp, accessed 1 September 2007. 
3. McCarthy, B., The 4MAT System: Teaching to Learning Styles With Right/Left Mode Techniques: EXCEL, Inc., 1987.

4. Kolb, D. A., Experiential Learning: Experience as the Source of Learning and Development, Prentice Hall, 1984.

5. Harb, J. N., Durant, S. O., and Terry, R. E., "Use of the Kolb learning cycle and the 4MAT system in engineering education," Journal of Engineering Education, vol. 82, No. 2, April 1993, pp. 70-77.

6. Hotaling, L., Sheryll, R., and Stolking, R., "Discovery based learning in the engineering classroom using underwater robotics," Proceedings of the ASEE Annual Conference and Exposition, Session 2006-78, 2006.

7. Bruner, J., Toward a Theory of Instruction, Harvard University Press, 1966.

8. Wang, E., LaCombe, J., and Rogers, C., "Using LEGO Bricks to Conduct Engineering Experiments," Proceedings of the ASEE Annual Conference and Exposition, Session 2756, 2004.

9. Chung, C. J. and Anneberg, L., "Robotics contests and computer science and engineering education," Proceedings of the $33^{\text {rd }}$ ASEE/IEEE Frontiers in Education Conference, Session F1F, Boulder, CO, November 2003.

10. Verner, I. M., and Ahlgren, D. J., "Fire-Fighting Robot contest: Interdisciplinary Design Curricula in College and High School," Journal of Engineering Education, vol. 91, No. 3, July 2002, pp. 255-359.

11. Flikkema, P., "Learning Embedded and Real-time systems via low-cost mobile robots," Proceedings of the ASEE Annual Conference and Exposition, Session 1332, 2001.

12. Klassner, F. and Andrson, S. D., "LEGO MindStorms: Not Just for K-12 Anymore," IEEE Robotics and Automation Magazine, vol. 10, No. 2, June 2003, pp. 12-18.

13. Goff, M., and Vernon, M., "Using LEGO RCX bricks as the platform for interdisciplinary design projects," Proceedings of the ASEE Annual Conference and Exposition, Session 3425, 2001.

14. Shih, A. and Hudspeth, M., "Using the LEGO robotics kit as a teaching tool in a project-based freshmen course," Proceedings of the ASEE Annual Conference and Exposition, Session 1353, 2001.

15. Gage, A. and Murphy, R., "Principles and experiences using LEGOs to teach behavioral robotics," Proceedings of the $33^{\text {rd }}$ ASEE/IEEE Frontiers in Education Conference, Session F4E, Boulder, CO, November 2003.

16. Self, B. P., Wood, J. J., and Hansen, D., "Teaching Undergraduate Kinetics using LEGO Mindstorms Race Car Competition," Proceedings of the ASEE Annual Conference and Exposition, Session 3668, 2004.

17. Bishop, B. E., "Teaching Robot Design: Locomotion Beyond Differential Drive," Proceedings of the ASEE Annual Conference and Exposition, 2005.

18. Bishop, B., Wick, C., and Piper, G., "Teaching Robot Design: Student-Driven, Open-Ended Design Projects," Proceedings of the ASEE Annual Conference and Exposition, Session 2006-1905, 2006.

19. Froyd, J., Li, X., Srinivasa, A., Bassichis, W., Hodge, J., and Maxwell, D., "How Do Students in a ProjectBased First-Year Engineering Curriculum Perform in a Sophomore Engineering Mechanics Course?," Proceedings of the ASEE Annual Conference and Exposition, Session 2006-1117, 2006.

20. Greenwald, L. and Kopena, J., "Mobile Robot Labs," IEEE Robotics and Automation Magazine, vol. 10, No. 2, June 2003, pp. 25-32.

21. N. Jaksic, D. Spencer, "An Introduction to Mechatronics Experiment: LEGO Mindstorms NXT Urban Challenge," 2007 ASEE Annual Conference, Honolulu, HI, June 24-27, 2007.

22. N. Jaksic, D. Spencer, "Mini Urban Challenge using LEGO Mindstorms NXT Autonomous Robots," Robotica 2007, The 7th Conference on Mobile Robots and Competitions, Paderne, Algarve, Portugal, April 27, 2007.

23. http://newtraditions.chem.wisc.edu/FLAG/downloads/drexel_faculty_form_4.doc, accessed on 1 December 2007. 